\title{
MANOVA for Distinguishing Experts' Perceptions about Entrepreneurship using NES Data from GEM ${ }^{1}$
}

\author{
Aldina Correia, Eliana Costa e Silva, Isabel C. Lopes and Alexandra Braga
}

${ }^{1}$ MANOVA for NES data from GEM

\begin{abstract}
Global Entrepreneurship Monitor is a large scale database for internationally comparative entrepreneurship that includes information about many aspects of entrepreneurship activities, perceptions, conditions, national and regional policy, among others, of a large number of countries. This project has two main sources of primary data: the Adult Population Survey and the National Expert Survey. In this work the 2011 and 2012 National Expert Survey datasets are studied. Our goal is to analyze the effects of the different type of entrepreneurship expert specialization on the perceptions about the Entrepreneurial Framework Conditions. For this purpose the multivariate analysis of variance is used. Some similarities between the results obtained for the 2011 and 2012 datasets were found, however the differences between experts still exist.
\end{abstract}

Keywords: Entrepreneurial phenomenon, Comparing multivariate sample means, additional views of EFCs PACS: $02.50 . \mathrm{Sk}, 02.50 . \mathrm{Tt}, 02.70 . \mathrm{Rr}$

\section{INTRODUCTION}

There exists a growing interest in several public and private initiatives for promoting entrepreneurial activity [1]. The Global Entrepreneurship Monitor (GEM) is a research program that focuses on a major driver of economic growth: entrepreneurship [2]. The purpose of this project is to use empirical data to assess the level of entrepreneurial activity across countries, to understand how entrepreneurial activity varies over time, and to understand why some countries are more entrepreneurial than others. Furthermore, GEM researchers seek to explore the relationship between entrepreneurial activity and economic growth and identify which public policies boost entrepreneurship. It started in 1999 with only 10 countries and since then it became the major database for internationally comparative entrepreneurship. Presently it includes data from more than 80 economies [3]. For this reason GEM makes possible to pose research questions that could not have been addressed before [4]. The 2015 GEM survey tracks, for the 17th year, the rates of entrepreneurship across multiple phases and assessed the characteristics, motivations and ambitions of entrepreneurs and the attitudes societies have toward this activity. The evolution of research based on the GEM project is provided in [1]. These authors identify the topics, units of analysis, and statistical techniques used. The two main sources of primary data of GEM are: the Adult Population Survey (APS), which provides standardized data on entrepreneurial activities and attitudes within each country, and the National Expert Survey (NES), which investigates the national framework conditions for entrepreneurship by means of standardized questionnaires. According to [1], 87\% of the articles use APS data, 3\% use the NES information, and 10\% use both information sources. Thus, it is clear that the NES information provided is an untapped resource for future publications. Regarding the statistical treatment, most of the empirical studies (42\%) use logit, probit and tobit models, $29 \%$ use multiple linear regression analysis associated with the macro level, $13 \%$ use panel data, and $16 \%$ use other techniques. Also according to [1], in most of the research articles the dependent variables are related to entrepreneurial activities in general (59\%), followed by papers that use indicators of entrepreneurial aspirations (14\%), and female entrepreneurship (10\%). These articles were followed by studies that use dependent variables related to economic issues, especially growth and economic development (5\%), and articles that attempt to explain perceptions of opportunities and motivations to become an entrepreneur (5\%). Finally, the remaining $7 \%$ use some financial aspect as the dependent variable. More than $70 \%$ of the articles use some kind of multivariate analysis techniques and a substantial variety of variables has been used as independent 
variables. Only a few studies have looked at the determinants of positive entrepreneurial attitudes and perceptions [4]. The statistic techniques used are mainly descriptive statistics, regression analyses, correlation analyses, logistical regression/logit, probit, or comparisons of means. Factor analysis, cluster analysis, or SEM were used less often. They justify this fact by the nature of the GEM data itself, largely consisting of single-items or dichotomous measures.

In this work, the 2011 and $2012^{2}$ NES Global Individual Level Data from GEM are studied. These are the most recent datasets available in GEM site. The effects that a different type of expert (i.e. Entrepreneur; Investor, Financer or Banker; Policy Maker; Business and Support Services Provider; Educator, Teacher or Researcher) has on the perceptions about the Entrepreneurial Framework Conditions (EFCs) and the variables corresponding to the opportunities, knowledge, culture, intellectual property, gender conditions, etc., in their own countries and/or regions, are analyzed using the multivariate analysis of variance (MANOVA).

\section{DATA ANALYSIS AND RESULTS}

In this work, the dependent variable, which defines the groups, is NES_SPE (computed from the dummy variables NES_SPE1, NES_SPE2, NES_SPE3, NES_SPE4 and NES_SPE5 available at GEM). This variable has 5 categories: $1=$ entrepreneur, $2=$ =investor, financer, banker, 3=policy maker, 4=business and support services provider and 5=educator, teacher, entrepreneurship researcher. All NES variables included in the EFCs (from NES_A1 to NES_I05) and other variables (from NES_K01 to NES_U04, in 2011 and from NES_K01 to NES_Y208, in 2012) are used as independent variables. MANOVA is performed using IBM SPSS, version 22. For the purpose of the MANOVA analysis, we will consider that the independent ordinal (likert scale) NES variables are continuous. This is a common procedure when working with real-world data, such as GEM data. The dependent variable (NES_SPE) satisfies the minimum of 2 categories, since it has 5 categories. An additional requirement for using MANOVA is that the frequency in each group is greater than the number of independent variables (97), as can be seen in Table 1. The univariate normality is not verified, however, since we have a large sample, we will assume an underlying approximately normal distribution, according to the Theorem of Central Limit.

TABLE 1. Table of frequencies of the NES_SPE variable.

\begin{tabular}{lcc|cc}
\hline $\begin{array}{l}\text { Categories of the } \\
\text { NES_SPE dependent variable }\end{array}$ & $\begin{array}{r}\mathbf{2 0 1 1} \\
\text { Frequency }\end{array}$ & $\begin{array}{r}\mathbf{2 0 1 2} \\
\text { Frequency }\end{array}$ & \% \\
\hline Entrepreneur & 727 & 39.3 & 1193 & 42.9 \\
Investor, Financer or Banker & 172 & 9.3 & 287 & 10.3 \\
Policy Maker & 284 & 15.3 & 400 & 14.4 \\
Business and Support Services Provider & 350 & 18.9 & 435 & 15.6 \\
Educator, Teacher or Researcher & 230 & 12.4 & 307 & 11.0 \\
$\quad$ Total & 1763 & 95.2 & 2622 & 94.2 \\
\hline Other & 89 & 4.8 & 161 & 5.8 \\
$\quad$ Total & 1852 & 100.0 & 2783 & 100.0 \\
\hline
\end{tabular}

Relatively to the homogeneity of variance-covariance matrices, for the 2011 dataset, the Box's Test of Equality of Covariance Matrices has a p-value $<0.05$, therefore the null hypothesis that the observed covariance matrices of the dependent variables are equal across groups is rejected, thus we have homogeneity of variance-covariance matrices. The p-value of Bartlett's Test of Sphericity is $0.000<0.05$, therefore the null hypothesis that the residual covariance matrix is proportional to an identity matrix is rejected, i.e., there are no signs of multicollinearity. The MANOVA was not statistically significant, since the Multivariate Tests table was not promising (Wilks Lambda p-value=0.261). For the 2011 dataset (Table 3), the variables which show significant differences between groups defined by NES_SPE are: NES_B02 - In my country, the support for new and growing firms is a high priority for policy at the national government level; NES_C03 - In my country, there are an adequate number of government programs for new and growing businesses; NES_C04 - In my country, the people working for government agencies are competent and effective in supporting new and growing firms; NES_C05 - In my country, almost anyone who needs help from a government program for a new or growing business can find what they need; NES_D03 - In my country, teaching in primary and secondary education provides adequate attention to entrepreneurship and new firm creation; NES_E06 - In my country, there is good support available for engineers and scientists to have their ideas commercialized

\footnotetext{
${ }^{2}$ Released on 2016.
} 
through new and growing firms; NES_F05 - In my country, it is easy for new and growing firms to get good banking services (checking accounts, foreign exchange transactions, letters of credit, and the like); NES_Q02 - In my country, policy-makers are aware of the importance of high-growth entrepreneurial activity; NES_T01 - There are no formal restrictions if you want to start a business using the resources, knowledge and contacts obtained from your current job as an employee; NES_U02 - The education system emphasizes innovative and pro-active behaviour of individuals in general. The results from a new MANOVA test peformed with only these variables are presented in Table 2 . There is homogeneity of variance-covariance matrices (Box's Test of Equality of Covariance Matrices p-value $=0.037<0.05$ ) and there is no signs of multicollinearity (Bartlett's Test of Sphericity p-value $<0.05$ ). The Wilks Lambda test has a pvalue $=0.000$, hence MANOVA for these variables is statistically significant. Therefore, we may conclude that different type experts have different perceptions of the effects on entrepreneurship of the variables under study. Furthermore, there are significant differences in these variables between the groups defined by NES_SPE (Tests of Between-Subjects Effects p-value $<0.1$, Table 3 ).

TABLE 2. MANOVA Results.

\begin{tabular}{lcc}
\hline Results & 2011 & 2012 \\
\hline Box's M sig & 0.037 & 0.066 \\
Bartlett's Test of Sphericity & 0.000 & 0.000 \\
Wilks' Lambda & 0.000 & 0.000 \\
\hline
\end{tabular}

TABLE 3. MANOVA - p-values of Tests of Between-Subjects Effects.

\begin{tabular}{clcccccc}
\hline Variable & & $\mathbf{2 0 1 1}$ & $\mathbf{2 0 1 2}$ & Variable & & $\mathbf{2 0 1 1}$ & $\mathbf{2 0 1 2}$ \\
\hline NES_SPE & NES12_A02 & & 0.000 & NES_SPE & NES11_D03 & 0.017 & \\
& NES12_A03 & & 0.000 & & NES11_E06 & 0.057 & \\
& NES12_B01 & & 0.000 & & NES11_F05 & 0.003 & \\
& NES12_B02 & 0.000 & & & NES11_Q02 & 0.000 & \\
& NES12_B05 & & 0.004 & & NES11_T01 & 0.008 & \\
NES11_C03 & 0.060 & 0.000 & & NES11_U02 & 0.006 & \\
& NES11_C04 & 0.003 & 0.000 & & NES12_R02 & & 0.097 \\
& NES11_C05 & 0.001 & & & NES12_W01 & & 0.000 \\
\hline
\end{tabular}

When analyzing Parameter Estimates and Post Hoc Tukey HSD tests (Table 4), we can see that there exist variables for which Policy Makers have more favorable perceptions than other type of experts, that are concerned with priority given for policy: NES11_B02, NES11_C03, NES11_C04, NES11_C05 and NES11_T01. The variable NES11_Q02 - In my country, policy-makers are aware of the importance of high-growth entrepreneurial activity is less favourable for Entrepreneur perceptions than other types of experts. For the variables concerning with education (NES11_ D03 and NES11_ U02), the Entrepreneur perceptions are less favourable than Investor, Financer or Banker. Relatively to support and services (NES11_ E06 and NES11_ F05), Entrepreneur perceptions are less favourable than Policy Makers.

There are considerable differences between the 2011 and 2012 NES - GEM datasets and the variables. For 2012 NES - GEM datasets, there is no available data for variables NES11_ T01 and NES11_ U02. Regarding the other variables, there are significant differences between groups for 2012 when compared to 2011. For 2012, a similar analysis was done (see Table 2). The variables that are significantly different between the groups are (see Table 5): NES12_A02 - In my country, there is sufficient equity funding available for new and growing firms; NES12_A03 In my country, there is sufficient debt funding available for new and growing firms; NES12_B01 - In my country, Government policies (e. g. , public procurement) consistently favor new firms; NES12_B05 - In my country, the amount of taxes is NOT a burden for new and growing firms; NES12_R02 - In my country, consumers like to try out new products and services; NES12_W01 - In my country public institutions often organize fairs and events where entrepreneurs meet and form contacts.

\section{DISCUSSION}

In this work, the 2011 NES survey is studied and some results are compared with the 2012 collected data. We compare the perceptions of different type of experts that participated in the survey. For this propose we used the multivariate analysis of variance (MANOVA), once the package IBM SPSS version 22 was already mentioned before.

We conclude that there are four variables concerned with priority given for policy, where policy makers have more favorable perceptions than other types of experts. 
TABLE 4. Multiple Comparisons - Tukey HSD Test for 2011.

\begin{tabular}{cccccc}
\hline Variable & Expertise $^{*}$ & Expertise & p-value & $I C_{95 \%} \mathbf{l b}$ & $I C_{95 \%} \mathbf{u b}$ \\
\hline NES11_B02 & 1 & 4 & 0.034 & -0.50 & -0.01 \\
& 3 & 1 & 0.000 & 0.34 & 0.86 \\
& & 2 & 0.000 & 0.20 & 0.91 \\
& & 4 & 0.013 & 0.05 & 0.64 \\
NES11_C03 & 1 & 5 & 0.005 & 0.09 & 0.75 \\
NES11_C04 & 3 & 1 & 0.028 & -0.51 & -0.02 \\
& & 4 & 0.001 & -0.56 & -0.10 \\
NES11_C05 & 3 & 1 & 0.000 & -0.61 & -0.14 \\
& & 4 & 0.029 & 0.14 & 0.61 \\
NES11_D03 & 1 & 2 & 0.015 & -0.50 & -0.03 \\
NES11_F05 & 3 & 1 & 0.003 & -0.61 & 0.03 \\
NES11_Q02 & 1 & 3 & 0.000 & -0.72 & -0.19 \\
& & 5 & 0.006 & -0.66 & -0.07 \\
NES11_T01 & 1 & 3 & 0.034 & -0.5200 & -0.0125 \\
NES11_U02 & 1 & 4 & 0.004 & 0.0849 & 0.6684 \\
& 3 & 2 & 0.016 & -0.5384 & -0.0363 \\
\hline
\end{tabular}

* 1 =entrepreneur, 2 =investor, financer, banker, 3 =policy maker, 4 =business and support services provider and $5=$ educator, teacher, entrepreneurship researcher

TABLE 5. Multiple Comparisons - Tukey HSD Test for 2012.

\begin{tabular}{cccccc}
\hline Variable & Expertise $^{*}$ & Expertise & p-value & $I C_{95 \%} \mathbf{l b}$ & $I C_{95 \%} \mathbf{u b}$ \\
\hline NES12_A02 & 1 & 2 & 0.008 & -0.52 & -0.05 \\
& & 3 & 0.029 & -0.42 & -0.01 \\
NES12_B01 & 1 & 4 & 0.000 & -0.52 & -0.11 \\
& & 3 & 0.000 & -0.56 & -0.17 \\
& & 5 & 0.004 & -0.44 & -0.05 \\
NES12_B05 & 1 & 3 & 0.012 & -0.48 & -0.04 \\
NES12_C03 & 1 & 3 & 0.011 & -0.58 & -0.05 \\
& & 3 & 0.001 & -0.54 & -0.09 \\
NES12_C04 & 1 & 5 & 0.000 & -0.52 & -0.11 \\
& & 3 & 0.000 & -0.52 & -0.12 \\
NES12_W01 & 2 & 4 & 0.000 & -0.54 & -0.11 \\
& 1 & 3 & 0.005 & -0.43 & -0.15 \\
& 3 & 3 & 0.000 & -0.60 & -0.07 \\
& & 5 & 0.009 & 0.05 & -0.16 \\
\end{tabular}

* 1 =entrepreneur, 2 =investor, financer, banker, 3 =policy maker, 4=business and support services provider and $5=$ educator, teacher, entrepreneurship researcher

The perceptions about the importance of high-growth entrepreneurial activity given by policy-makers are less favorable for entrepreneur perceptions than other types of experts. The results obtained for the 2011 and 2012 datasets have some similarities, and the differences between the perceptions of the different types of experts in the entrepreneurial indicators still exist.

\section{REFERENCES}

1. C. Álvarez, D. Urbano, and J. Amorós, Small Business Economics 42, 445-465 (2014), ISSN 0921898X.

2. P. Reynolds, N. Bosma, E. Autio, S. Hunt, N. De Bono, I. Servais, P. Lopez-Garcia, and N. Chin, Small Business Economics p. 205 (2005), ISSN 0921898X.

3. N. S. Bosma, J. Levie, et al. (2010).

4. H. Bergmann, S. Mueller, and T. Schrettle, International Journal of Entrepreneurial Venturing 6, 242-276 (2014). 